\section{Original Research}

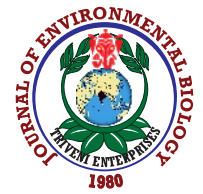

DOI : http://doi.org/10.22438/jeb/41/2(SI)/JEB-26
Journal Home page : www.jeb.co.in $\star$ E-mail : editor@jeb.co.in

\section{Journal of Environmental Biology}

p-ISSN: 0254-8704

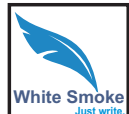

\title{
The influence of green areas on city-dwellers' perceptions of air pollution: The case of Nigde city center
}

\section{Ç. Çetin ${ }^{1 *}$ and F.C. Karafakı ${ }^{2}$}

'Department of Interior Architecture and Environmental Design, Yasar University, Izmir, 35100, Turkey

2Program of Tourism and Hotel Management Program Introduction, Ankara University, Ankara, 06730, Turkey

*Corresponding Author Email : cigdem.cetinkaya@yasar.edu.tr

\section{Abstract}

Aim: The aim of the stıdy was to determine the effect of green areas in order to improve the quality of life and create positive perceptions on air quality by modifying physical and social environments within the cities.

Methodology: Literature research, official data and a semi structured questionnaire conducted with the citizens of Nigde were used. SPSS version 21.0 was used for data evaluation.

Results: Findings indicated that green spaces could reducethe negative perception about poor air quality. Even if official authorities do not report air pollution, the lack of green space in the city center influences the perception of air quality in negative way.

Interpretation: Green spaces in convenient number, size and quality should be included in city centers for improving the quality of life in cities.

Key words: Air quality, Air pollution, City dwellers, Green spaces, Nigde city

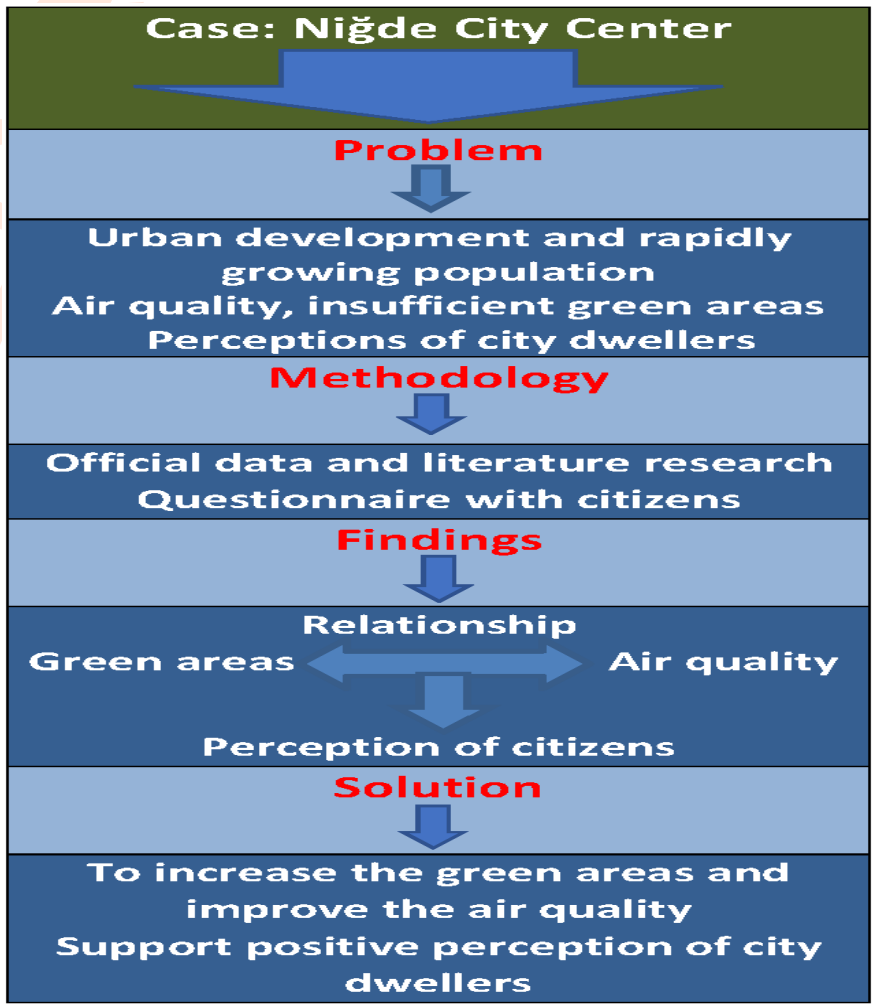

How to cite : Çetin, C. and F.C. Karafakı: The influence of green areas on city-dwellers' perceptions of air pollution: The case of Nigde city center. J. Environ. Biol., 41, 453-461 (2020). 


\section{Introduction}

A city can be connected to nature by various natural assets, such as forest areas, coppice forests vineyards, orchards, agricultural fields, cemeteries, green areas like city parks, archeological (underground cities, arches) and historical areas (national nature parks, natural monuments, wetlands, wildlife reserves, etc.), footpaths, amusement parks, neighborhood parks and playgrounds. At the same time, they increase the quality of city life through their social and economic value. However, the quality of city life depends not only on its social and economic environments but also on physical and ecological environments.

The quality of urban life depends on the interaction of society, economy and environment, which can be measured by both subjective and objective evaluation criteria. It has been suggested that objective criteria apply to physical, social and economic functions whereas subjective criteria refer to various aspects of personal life, such as desires, expectations, happiness and pleasure (Ozturk and Ozdemir, 2013).

Accordingly, research focusing on the quality of life can be categorized by applying physical (Smith et al., 1997; Mohadeseh et al., 2015), social (Zenker and Rutter, 2014; Turksever and Atalik, 2001; Theodori, 2004; Berntze and Johannessen, 2016) and economic (Brunelle, 2013; Addanki and Venkataraman, 2017; Pratt and Hutton2013) criteria. Some studies have investigated the quality of cities in a more compherensive way (Kaklauskas et al., 2018; Węziak-Białowolska, 2016; Essam and Khalil, 2012). However, they are measured, all these criteria refer to human happiness so many researchers have established a connection between such forms of happiness and quality of life in cities (Ballas and Dorling, 2013; Ballas and Tranmer, 2012; Baum et al., 2010). In parallel with this academic literature, the problem of life quality in cities has become more important in the policies of European Union countries in recent years (Węziak-Białowolska, 2016). Although the natural sciences and humanities have been examined separately in the past, cultural and natural phenomena should be examined together for a quality life (Ozguc and Tumertekin, 2000). Thus, drawing on these developments, this study aims to investigate the quality of life in one city from the perspective of its citizens.

As mentioned above, the quality of life in cities are affected by various factors. As natural urban areas in cities, green areas are one important factor affecting life quality, both physically and socially. This study mainly focused on the following research questions:

\section{Q1: What are the parameters affecting city life quality?}

Q2: What is the effect of air quality on perceptions of city life quality?
Q3: How do urban green areas influence perceptions of air pollution?

The ways people perceive urban areas and how they use them vary according to several parameters. Individual, environmental and social factors are all important for changing people's attitudes, which affect their perceptions of the city. The main individual traits influencing perceptions of a place are physical structure, sex, age, customs, culture, habits, social class-dependent experiences, education level, and also feelings and purposes when the person is stimulated by the stimulus.

Perceptions of urban areas can be evaluated in terms of their physiological and psychological effects under individual, environmental and sociological contexts. It affects a person's psychological bond with the space when the person has an experience in or around the space within a long or short time and remembers the space accordingly. The concepts of motion and time alter this experience. The person's position in a space helps him or her to communicate with the space and to analyze spatial relationships (Ozen, 2006).

Several concepts should be considered in urban areas, where human-space interactions develop on social basis. These include effectiveness (integrity and sensitivity), productivity (speed and occupation), relationship (satisfaction and pleasure), error margin (preventing or correcting mistakes), and learnability (foreseeability and consistency). These factors refer to humanitarian values, improve security and enhance the user's comfort by improving quality of space (Dimitriadis et al., 2006). Additionally the external factors such as the characteristics of individual (age, social status, etc.) using urban areas, security, environmental awareness to the environmental issues (air, water and noise pollution, unplanned urbanization, etc.), and seasonal variations are effected on human-space interactions.

Air quality, which is one of the most important measures of environmental quality, is the primary requirement or city dwellers' survival. All living beings have the right to breathe fresh air. Yet various polluters, particularly in large cities, contaminate the air and turn it into a threat to human life.

Air pollution may increase to a level that various constituents, such as dust, gases, smoke, scents and water vapor, become dangerous for both ecological balance, humans as well as other living organisms. Air becomes dangerous for nature and living organisms when pollutants and foreign objects in the atmosphere increase (Ilhan et al., 2006). Europe, for example, has focused attention on this issue:

"The European Union has long recognised the need to tackle issues affecting the air we breathe. These policy tools have played a significant role in reducing concentrations in ambient air of harmful pollutants such as sulphur dioxide $\left(\mathrm{SO}_{2}-\right.$ the main 
cause of acid rain), particulate matter (PM10), lead, nitrogen oxides ( $\mathrm{NOx}-\mathrm{NO}$ and $\mathrm{NO}_{2}$ ), carbon monoxide and benzene. Thus, in December 2013, the European Commission adopted a new clean air policy package designed to update existing legislation and further reduce harmful emissions from anthropogenic sources with a view to reduce their impact on human health and environment (Camarsa et al., 2014)".

Several studies have raised global awareness about air pollution that has influenced urban residents as their results have been disseminated by the media and educational institutions. This has harmed city dwellers psychologically by making them fear the effects of air pollution on their health, especially due to depletion of clean resources and use of toxic gases. Such people are affected in many ways since these perceptions are not only visual but also dimensional, textural, thermal, olfactive and audial (Zengel and Kaya, 2007).

Green areas in cities have some positive effects on urban ecosystems by improvingair quality by increasing relative air humidity, filtering air, producing oxygen, cooling air and offsetting greenhouse effects (Barıs, 2005). It is well known that urban green areas naturally extract pollution from the air and can provide cooler, cleaner air to the city (Zupancic et al., 2015). Recent studies (Roy et al., 2012; Konijnendijk et al., 2013; Bowler et al., 2010) have demonstrated the value of urban trees, parks and green space generally to reduce heat, ozone and ultraviolet (UV) radiation in urban areas (Zupancic et al., 2015).

According to Donka et al. (2017), besides its physical effects, good urban planning relates to public health socially and psychologically by decreasing the psychological stress caused by environmental pollution. They argue that green spaces have "exposure" on the citizens' perceptions of air pollution. Thereby, the effects of green areas on perceptions of air quality can be analyzed in two respects: strategies for reducing perception of air pollution; strategies for adaptation of green areas to minimize pollution (Table 1).

Table 1 : Effects of reduction and adaptation strategies on perceptions of urban air pollution

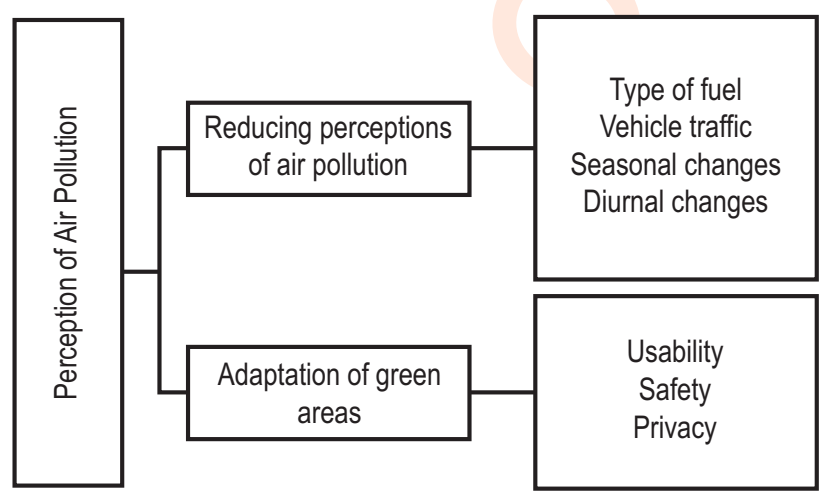

\section{Materials and Methods}

Nigde is located in the Central Kızılırmak Region of Central Anatolia, Turkey. In the present study, it was selected as the study area. As per 2014 census, the population was 343,898 , with 149,696 number of people residents living in the city itself (Anonymous, 2015a). According to the World Health Organization, there should be at least $9 \mathrm{~m}^{2}$ of green area per city resident and 10-15 $\mathrm{m}^{2}$ ideally (Anonymous, 2015b). However, the green areas in Nigde fall far below these levels, as compared to other cities of Turkey.

The population density of Nigde is 47 people $\mathrm{m}^{-2}$, which is

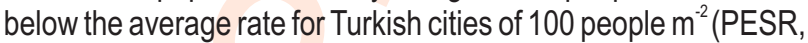
2015). Nevertheless, the city center cannot meet the recreational needs of Nigde's population. Nigde's population has increased by $13.7 \%$ over a year, which is also less than the average rate for Turkey (Turkish Statistical Institute, 2013).

The central district where most of Nigde's population reside is the city's main attraction with its historical city center, downtown, major official or governmental buildings, health and education institutions, and commercial activities. Although in this city center, which is of great civic value, there are few areas that can enhance the quality of life of city dwellers'. Fortunately, residents living in the suburbs enjoy a sense of spaciousness due to less construction; however, the city center is deprived of green spaces. Accordingly, this study examined the city's existing large and small parks, picnic areas, a social foundation complex and city forest, which are already used by citizens provide valuable green areas.

The data used in the study were acquired from a literature research, official data and a questionnaire. The literature review focused on life quality, perception of city life quality, air quality and city green spaces.

As mentioned in the introduction, two classifications "reduction" and "adaptation" were applied for the questionnaires to evaluate the physical and psychological effects of green areas on perceptions of air quality (Liu and Hen, 2014). From this data, several strategies for reducing the negative perception of air pollution and adapting green spaces to influence perceptions of air quality were determined.

To improve the reliability of the study, data was used from the Special Provincial Administration of Nigde, Provincial Directorate of Culture and Tourism, Nigde Municipality Parks and Recreation Department, Nigde Municipality Housing and Urbanization Department and the Turkish Statistical Institute.

To evaluate how green areas in Nigde's city center affected the perception of air quality, semi-structured questionnaire/interview (Bargali et al., 2009; Pandey et al., 2011; Parihaar et al., 2014) was conducted with 100 people with a random sample of residents, with the sample size based on the city center population of 149,696 , as mentioned earlier since only city center green areas were included within the scope of this study. 
The questionnaire had two main parts: an introductory section to collect demographic information and the main section about reduction and adaptation. The multiple choice, openended and dichotomous questions were conducted within the questionnaire.

\section{Results and Discussion}

Air pollution caused by urbanization has global, regional and local effects. Currently, great emphasis is being put on air quality worldwide since air pollution has important deleterious effects on human health. Under the Air Quality Index, a globally recognized classification system, air quality is rated from good to dangerous, depending on specific air pollutant concentrations. Turkey's National Air Quality Index is an adaptation of the US EPA's Air Quality Index, national legislation and limiting values. The index is calculated for five main air pollutants: particulate matter (PM10), carbon monoxide (CO), sulphur dioxide $\left(\mathrm{SO}^{2}\right)$, nitrogen dioxide $\left(\mathrm{NO}^{2}\right)$ and ozone $\left(\mathrm{O}_{3}\right)$. Table 2a shows the air quality index and the assessment of air pollution according to the level of pollutants in air and Table $2 \mathrm{~b}$ shows the meaning of the colors symbolizing pollutants and the effects of these pollutants on population for each index (PESR, 2015).

On the website of Air Quality Monitoring Stations created within the Turkish Ministry of Environment and Urbanization that presents data for the air quality index and air quality monitoring stations (Fig. 1), Nigde's air quality is shown as good (green)i.e., Nigde's air quality is pleasant with little or no health risk from air pollution (PESR, 2015).
Air pollution measurement station which measures particulate matter (dust) and sulphur dioxide $\left(\mathrm{So}_{2}\right)$, is located in the garden of the City Directorate of Meteorology. Fig. 2, 3 presents the station's 2014 data for $\mathrm{PM}_{10}$ and $\mathrm{SO}_{2}$ (PESR, 2015).

As Fig. 2 and 3 shows, $\mathrm{PM}_{10}$ value for most of the months over a year and $\mathrm{SO}_{2}$ values in each month over a year are below their respective permissible limit in Nigde city center. Nigde City Environment Status Report of 2015 evaluated the status of air pollution in the city in terms of air parameters that could be measured in the city. These pollutants were evaluated within the range of six separate air quality indices in terms of National Air Quality Index (PESR, 2015). The 12-month average $\mathrm{SO}_{2}$ level was 6.08 day, while the limit value never exceeded on any day; the 12-month average PM10 level was 68.4; the DEL (day of exceed the limit) value was three days (PESR, 2015). Based on these values, air pollution in Nigde is unlikely to have a negative effect on the city's eco-system.

Results and Evaluation of Questionnaire : According to the demographic data of the participants, 50\% residents aged between $26-45$ years, $60 \%$ were married, $48 \%$ were university graduates, $57 \%$ were working and $38 \%$ earned between 1000 and 3000 TL per month.

The second part of the questionnaire asked about the participants' general views about air quality and green areas. Regarding the most serious environmental problem, they perceived in Nigde city centre, the responses were as follows: unplanned urbanization (24\%), environmental pollution (22\%)

Table 2a: National Air Quality Index and assessment of air pollution according to the level of pollutants in air (PESR, 2015)

\begin{tabular}{|c|c|c|c|c|c|c|}
\hline INDEX & NAQI & $\begin{array}{l}\mathrm{SO}_{2}\left[\mathrm{\mu gm}^{-3}\right] \\
1 \text { per hour }\end{array}$ & $\begin{array}{l}\mathrm{NO}_{2}\left[\mathrm{\mu gm}^{-3}\right] \\
1 \text { per hour }\end{array}$ & $\begin{array}{l}\mathrm{CO}\left[{\left.\mu \mathrm{gm}^{-3}\right]}{ }^{8 \text { per hour }}\right.\end{array}$ & $\begin{array}{l}\mathrm{O}_{3}\left[\mathrm{\mu gm}^{-3}\right] \\
8 \text { per hour }\end{array}$ & $\begin{array}{l}\mathrm{PM}_{10}\left[{\mu \mathrm{gm}^{-3}}^{-3}\right. \\
24 \text { per hour }\end{array}$ \\
\hline GOOD & $0-50$ & $0-100$ & $0-100$ & $0-5500$ & $0-120 \mathrm{~L}$ & $0-50$ \\
\hline MEDIUM & $51-100$ & $101-250$ & $101-200$ & $5501-10000$ & $121-160$ & $51-100 \mathrm{~L}$ \\
\hline CRITICAL & $101-150$ & $251-500 \mathrm{~L}$ & $201-500$ & $10001-16000 \mathrm{~L}$ & 161-180B & $101-260 U$ \\
\hline UNHEALTY & $151-200$ & $501-850 U$ & $501-1000$ & $16001-24000$ & $181-240 U$ & $261-400 U$ \\
\hline BAD & $201-300$ & $851-1100 \mathrm{U}$ & $1001-2000$ & $24001-32000$ & $241-700$ & $401-520 \mathrm{U}$ \\
\hline DANGEROUS & $301-500$ & $>1101$ & $>2001$ & $>32001$ & $>701$ & $>521$ \\
\hline
\end{tabular}

L: Limit value; B: Information threshold; U: Warning Threshold; $\mu \mathrm{g} \mathrm{m}^{-3}$ : Micrograms per cubic meter of air, per hour: Indicate the level of pollutants in outdoor air over an hour

Table $2 \mathrm{~b}$ : Meaning of colors symbolizing pollutants and the effects of these pollutants on population for each index

\begin{tabular}{ll}
\hline Color & Meanings \\
\hline GREEN & Air quality is pleasant and air pollution bears little or even no risk. \\
YELLOW & Air quality is decent, yet for those who are over- sensitive to air pollution, there may be a health concern. \\
ORANGE & Some health effects may appear for sensitive groups. It is not possible that public may be affected. \\
RED & Everyone may have health problems. Those who are sensitive may face sersous health problems. \\
PURPLE & Urgency terms may be promulgated. It is highly possible forthe whole population may be affected. \\
BROWN & Health alarm: Everyone may confrontmore serious health effects. \\
\hline
\end{tabular}




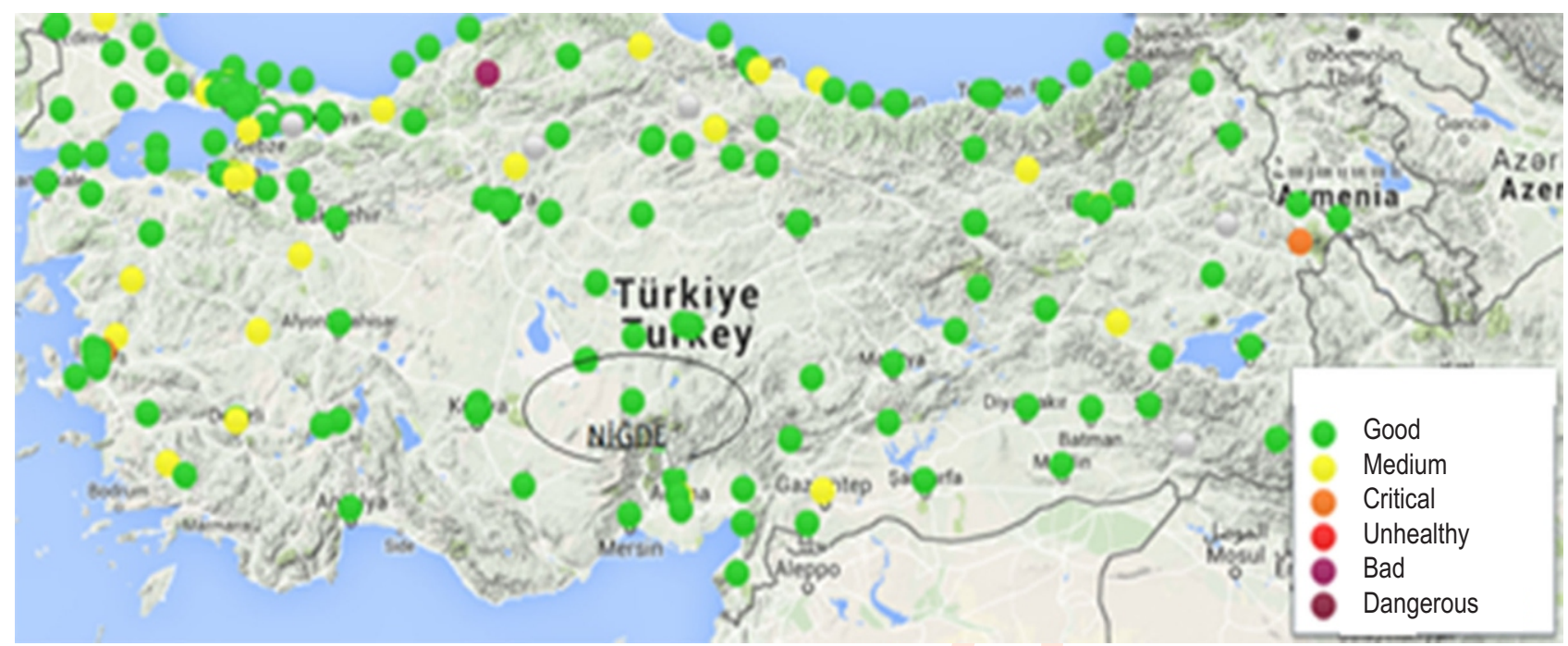

Fig. 1 : Air Quality Index for Nigde according to air condition monitoring data for Turkey (PESR, 2015).

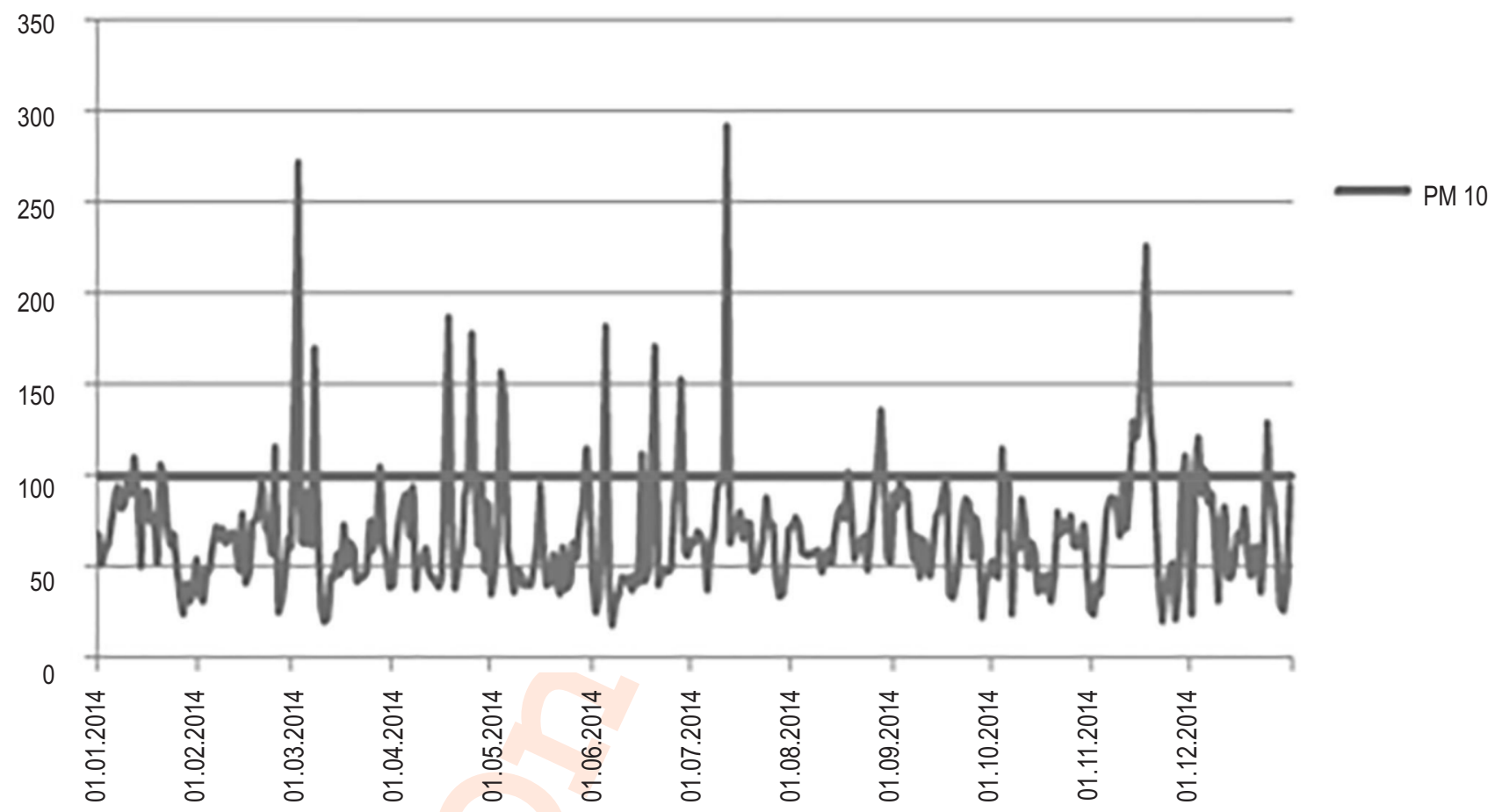

Fig. 2 : PM $_{10}$ parameters and 2014 daily average values for Nigde Central Station (PESR, 2015).

and air pollution (19\%), while $65 \%$ of participants complained of polluted air in Nigde city. From the replies it can be concluded that unplanned construction in urbanization, environmental pollution and air pollution are perceived in close proximity to each other as an important problem by the city, and that this is why air pollution is considered in Nigde city center.

Two questions were asked to participants about green areas of Nigde. First, whether Nigde was a green city or not, to which $80 \%$ disagreed that Nigde was a green city in their opinion and $20 \%$ agreed that Nigde was a green city. Second, whether green areas in Nigde city center were sufficient or not, to which $89 \%$ participants disagreed that the green areas in Nigde city centre were sufficient and $11 \%$ agreed that the green areas in Nigde city centre were sufficient.

After asking about the air quality and its connection with green spaces, participants were asked about strategies on 


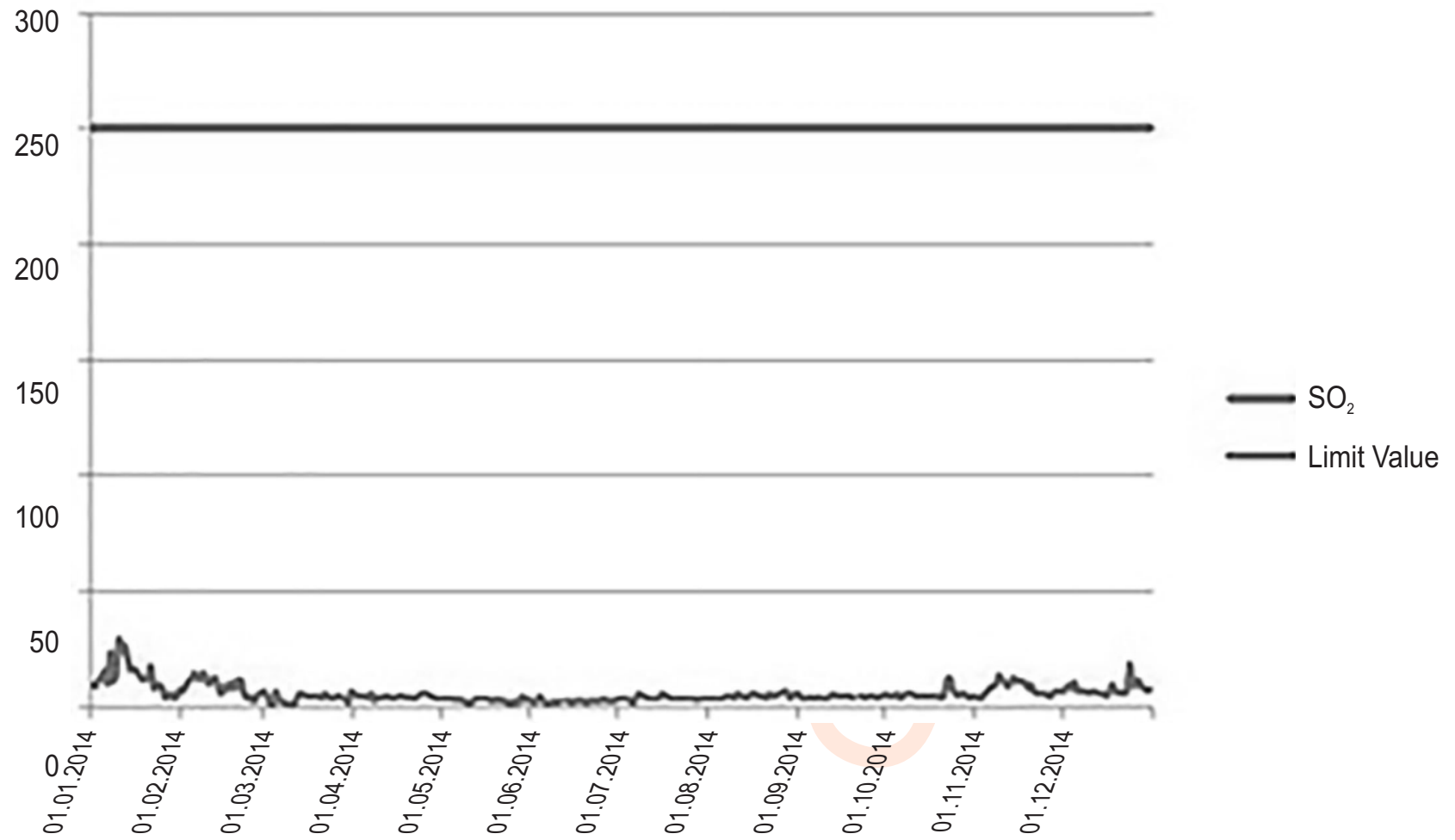

Fig. 3 : $\mathrm{SO}_{2}$ parameters and 2014 daily average values for Nigde central station (PESR, 2015).

reducing negative perception on air pollution; $65 \%$ of the participants agreed of polluted air in Nigde, while the main reason suggested were fuels used in the city ( $40 \%$ of participants) and vehicles (28\%), 32\% gave no reason. Finally, $65 \%$ claimed that air pollution was worse in the city center, while $5 \%$ believed that air was worst outside the city center.

Regarding seasonal differences in perceptions of air pollution, $17 \%$ of participants claimed it was worst in summer whereas $50 \%$ said winter, with $33 \%$ offering no opinion. Regarding changes in perceptions of air pollution during each day, $11 \%$ stated air pollution during morning time, $14 \%$ at noon, $3 \%$ in the evenings whereas $32 \%$ gave no comment. Among the reasons for these perceptions were shorter days in winter, meaning that is is already dark when office hours end, the increased air pollution at these times due to vehicle traffic increases and leaf fall because of winter. Almost half of participants believed that combust in of coal for air pollution. City residents use coal in winters, especially for heating purpose, which negatively affects them due to emission of black smoke and also its smell. Further, participants were also asked about the adaptation of green spaces by the city.

As a large and accessible green, Nigde City Forest was included in the questionnaire, with $68 \%$ of participants stating that they used this amenity. Regarding their awareness about the effect of the city forest on air quality, $75 \%$ agreed that it provides clean air for the city while $46 \%$ agreed that it controls the winds prevailing over the city. In parallel, it was seen that the city forest was used as clean air source by Nigde residents. City forests formed a barrier against winds due to mass of trees and scatter blustery winds, directing them towards open places rather than city. City forests also scatter polluted air emitted from around the city by controlling the city winds.

As mentioned in the introduction, one of the criteria regarding adaptation of green spaces by the city is safety. However, $77 \%$ of participants disagreed that the parks in the city center are safe. For convenient day and night time use, a safe perception of parks is an important parameter. However, $79 \%$ of participants felt that they cannot use city's parks both at day and night time. Use of any space is directly related to the person feeling safe. If people need to limit their behavior because of percieving there as insecure for themselves and the ones they are responsible for, reducing the time they spend in the place. To alleviate such anxiety and make these green spaces suitable for users at any age and either gender designs should facilitate recreation for almost 24 hrs (by considering plant occlusion, by removing any blind spots, by ensuring sufficiently frequent and bright lighting throughout the place, and by security monitoring). 
In addition, in-park circulation should be designed not to upset people and enable them to find their way, with map notices provided so that people do not feel they will get lost. Finally, both standing and patrolling security staff should be provided where usage is high.

"Privacy" was the other criterion for adaptation. Pecautions taken for the security may damage the privacy phenomenon of people by violating their personal boundaries. Therefore, security precautions considering privacy should be implemented in public places such as parks, gardens etc., in the city. Since it is the largest piece of green space located close to Nigde city center and accordingly its easy access, the usability of Nigde City Forest was questioned in the context of the study. Despite its location and advantage for access; $68 \%$ of participants reported that they do not use Nigde city forest.

Drawing on the questionnaire, the causes of the gap between official reports and the Nigde residents' perceptions of air pollution separately for each question were evaluated to note the following problems: inadequate number of unevenly distributed green areas across the city; limited variety and number of green materials; inability to appeal to the urban population, with its diverse demographic characteristics, due to the inadequacy of the existing green area facilities; inability of green areas within the city to be noticed by residents because of other city components (buildings, building heights, street widths, number of vehicles, car parking zones, public buildings); lack of definition of green areas or green belt within city borders; insufficient use of green areas to create appropriate distance between city and industrial areas and perception of buildings as concrete piles because landscaping of public buildings not considered together with green materials

Besides, the fact that visible surfaces in the city center are not evaluated with green material, even if they are not active green areas, also reduce the green perception.

Various solutions to the above problems were proposed: increase the number of green areas and their visibility to provide a homogeneous distribution within the city; increase the number and variety of greenery used; increase the number and diversity of existing equipment in green spaces; bordering the city with green areas or a green belt while excluding industrial areas from this belt; introduce balanced co-use of the green and built environments within the city; minimize the gap that causes a sense of insecurity as people leave buildings by using greenery; add intense screening plants, diminish the dirty image created by industrial areas, construction sites, waste dumps, parking lots and the adverse effects of vehicle traffic and urbanization

In conclusion, although $\mathrm{PM}_{10}$ and $\mathrm{SO}_{2}$, which are two of the most important parameters of air quality, are under the limit values in Nigde, the city's residents have a strong perception of air pollution. This may stem from the perception of unhealthy conditions of living in the city center. Inadequacy of green areas, both qualitatively and quantitatively, is the most important factor distorting people's perceptions of the city. Green areas can provide many ecological, economic and sociological advantages within the city, hence, their absence may prevent these advantages being achieved and leads to the perception that the city's living conditions are unhealthy.

Therefore, it would be very useful to expand existing green areas within the city, improve their facilities both qualitatively and quantitavively and try to forest these areas appropriately for Nigde's climatic conditions. If the city's official institutions and organizations, schools, parks and recreation areas, children's playgrounds and sports fields are forested with plant species resistant to air pollution then this will strengthen people's perceptions of green areas in the city, which will improve the citizens' satisfaction with the city they live in.

A city is percieved in many different ways by its residents, city planners or visitors. While citizens perceive first the house they live in, the street, the neighborhood, the district and finally the city, a visitor experiences these localities in the opposite order. This contrast causes some misconceptions about how citizens perceive the problems they believe exist and what they feel is good in cities. Given this situation, this study contributes to the field by questionning the opinions of the residents of one city in Turkey. Furthermore, the study also identifies and applies various criteria for reduction and adaptation of green areas to understand the subjective perceptions of citizens regarding air quality and green spaces, which play a crucial role in life quality. Finally, by using not only literature and questionnaire data but also official data, this study can be an important reference for future research.

To conclude, if the number, size and quality of urban green areas - which are important contributors to the city psychologically, physiologically and aesthetically and used by every segment of society - are insufficient then this can make residents have more negative perceptions of the city's air quality regardless of objectively measured levels of pollution. Therefore, to change perceptions, green spaces should be designed to be safe and convenient while, catering to diverse categories of users at different times of day and season.

\section{Acknowledgments}

We would like to thank Manucipality of Nigde, Nigde Provincial Special Administration, Nigde General Directorate of Meteorology and Nigde Provincial Directorate of Environment and Urbanism for their permission and support to use data. 


\section{References}

Addanki, S.C. and H. Venkataraman.: Greening the economy: Areview of urban sustainability measures for developing new cities. Sustain. Citi. Soc., 32, 1-8 (2017).

Akten, M.: Determination of the existing potentials of some recreational areas in Isparta province. Suleyman Demirel Univ. J. Facul. Fores., A(2), 115-132 (2003).

Anonymous a. (2015).www.Nigde.Gov.Tr/ Population-And-Distribution. $\mathrm{Html \# .Vqnantksvlw.} \mathrm{Accessed} 11$ February 2015.

Anonymous b. (2015).www.who.int. Accessed 27 December 2015.

Ballas, D. and M. Tranmer: Happy people or happy places? A multilevel modeling approach to the analysis of happiness and well-being. Int. Region. Sci. Rev., 35, 70-102 (2012).

Ballas, D. and D. Dorling: The Geography of Happiness. In: The Oxford Hadbookof Happiness (Eds.: S. David, I. Boniwell and A. Conley). Oxford University Press, Oxford, pp. 465-481 (2013).

Bargali, S.S., K. Pandey, L. Singh and S.K. Shrivastava: Participation of rural women in rice based agroecosystem. Inter. Rice Res. Notes, 33, 1-2 (2009).

Barıs, M.E.: Urban planning, urban ecosystem and trees, planning. J. Chamber of City Plann., 4, 156-163 (2005).

Baum, S., K. Arthurson and K. Rickson: Happy people in mixed-up places: the association between the degree and type of local socioeconomic mix and expressions of neighbourhood satisfaction. Urban Stud., 47, 467-485(2010).

Berntzen L. and M. Johannessen: The role of citizen participation in municipal smart city projects: lessons learned from Norway. In: Smarter as the new urban agenda (Eds.: J. Gil-Garcia, T. Pardo and T. Nam). Public Administration and Information Technology, Springer, Norway (2016).

Bowler, D., L. Buyung-Ali, T. Knight and A.S. Pullin: How effective is greening of urban areas in reducing human exposure to ground level ozone concentrations, UV exposure and the "urban heat island effect. CEE Rev. Environ. Evid., 08-004 (SR41) 0-92 (2010).

Brunelle, C.: The growing economic specialization of cities: Disentangling industrial and functional dimensions in the Canadian urban system, 1971-2006. Growth and Change, 44, 443-473 (2013).

Camarsa, G., J. Toland, T. Hudson, S. Nottingham, W. Jones, M. Moliver, A. Kāla, A. Rubene and C. Thévignot: Life and air quality. Publications Office of the European Union Luxembourg (2014).

Dimitriadis, Y.A., Zigurs I., Gómez-Sánchez and E. Groupware: Design, implementation and use. $12^{\text {th }}$ International Workshop, Criwg 2006, Medina Del Campo, Spain (2006).

Donka, D., A. Dimitrova and M. Dzhambov: Perceived access to recreational/green areas as an effect modifier of the relationship between health and neighbourhood noise/air quality: results from the 3rdeuropean quality of life survey (Eqls, 2011-2012). Urb. For. Urb. Gree., 23, 54-60 (2017).

Essam, H., A. and E. Khalil: Enhancing quality of life through strategic urban planning. Sustainable Cities and Society, 5, 77-86 (2012).

Ilhan, A.I., N. Oz, C. Dundar, F. Kenet and T.T.C. Balta: Ministry of environment and forestry general directorate of state meteorology affairs technical report acid rainfalls and air pollution assessment report. Research and Computer Center Directorate Research Department Acid Rain and Air Pollution Working Group, 1-2 (2006).
Kaklauskas, A., E.K. Zavadskas, A. Radzeviciene, I. Ubarte, A. Podviezko, V. Podvezko, A. Kuzminske, A. Banaitis, A. Binkyte and V. Bucinskas: Quality of city life multiple criteria analysis. Cities, 72, 82-93 (2018).

Kalıpsız, A.: Statistical Methods. IU. Faculty of Forestry Publication, Istanbul, Turkey (1981).

Karasar, N.: Scientific Research Method, Concepts, Principles. Techniques. Sanem Printing, Ankara, Turkey (1991).

Konijnendijk, C.C., M. Annerstedt, A.B. Nielsen and S. Maruthaveeran: Benefits of urban parks: A systematic review. A Report for Ipfra, 3134 (2013).

LIU, H.L. and Y.S. Shen: The impact of green space changes on air pollution and microclimates: A case study of the Taipei metropolitan area. Sustainability, 6, 8827-8855 (2014).

Mohadeseh, M., A. Faizah and A. Bushra: Livable streets: The effects of physical problems on the quality and livability of Kuala Lumpur streets. Cities, 43, 104-114 (2005).

Ozdamar, K.: Modern scientific research methods. Kaan Bookstore, Eskisehir, Turkey (2003).

Ozen, A.: Perception psychology in architectural virtual reality environments. Information technology congress iv. academic information, Denizli, Turkey (2006).

Ozguc, N. and E. Tumertekin: Geography, history, concepts, geographers. Cantay Bookstore, Istanbul, Turkey (2000).

Ozturk, S. and Z. Ozdemir: The effects of urban open and green spaces on life quality. A case study of Kastamonu. Kastamonu Univ. J. Facul. Fores., 13, 109 (2013).

Pandey, K., S.S. Bargali and S.S. Kolhe: Adoption of technology by rural women in rice based agroecosystem. Inter. Rice Res. Notes, 36, 1$4(2011)$

Parihaar, R.S., K. Bargali and S.S. Bargali: Diversity and uses of ethnomedicinal plants associated with traditional agroforestry systems in Kumaun Himalaya. Indian J. Agricult. Sci., 84, 1470-1476 (2014).

PESR: Provincial environmental status report, Governorship of Nigde. Provincial Directorate of Environment and Urbanism, pp. 17-19, Nigde, Turkey (2015).

Pratt, A.C. and T.A. Hutton: Reconceptualising the relationship between the creative economy and the city: learning from the financial crisis. Cities, 33, 86-95 (2013).

Roy, S., J. Byrne and C. Pickering: A systematic quantitative review of urban tree benefits, costs, and assessment methods across cities In different climatic zones. Urban Fores. Urban Green., 11, 351363 (2012).

Sandal, E.K. and N. Karademir: Determination of people's expectations and consciousness with adequacy of green spaces in Kahramanmaras. East. Geograp. Rev., 29, 155-176 (2013).

Smith, T., M. Nelischer and N. Perkins: Quality of an urban community: A framework for understanding the relationship between quality and physical form. Landsc. Urban Plann., 39, 229-241 (1997).

Theodori, G.L.: Community attachment, satisfaction and action. J. Comm. Develop. Soc., 35, 73-86 (2004).

Turkish Statistical Institute: Nigde with selected visuals 2013. Turkish Statistical Institute Publications, Ankara, Turkey (2013).

Turksever, A.N.E. and G. Atalik: Possibilities and limitations for the measurement of the quality of life in urban areas. Soc. Indicat. Res., 53, 163-187 (2001).

Węziak-Białowolska, D.: Quality of life in cities empirical evidence in 
comparative European perspective. Cities, 58, 87-96 (2016).

Zengel, R. and I. Kaya: Effects of color perception on space, material in architecture. Chamber of Arch. Publicat., 6, 26-31 (2007).

Zenker, S. and N. Rutter: Is satisfaction the key? The role of citizen satisfaction, place attachment and place brand attitude on positive citizenship behavior. Cities, 38, 11-17 (2014).

Zupancic, T.: The impact of green space on heat and air pollution in urban communities: A meta-narrative systematic review, Habitus Research Claire Westmacott, Research Coordinator Mike Bulthuis, Senior Research Associate, Vancouver, Bc. (2015). 